\title{
Relative cost-effectiveness of using a liquid human milk fortifier in preterm infants in the US
}

This article was published in the following Dove Press journal:

ClinicoEconomics and Outcomes Research

4 January 2017

Number of times this article has been viewed

\author{
Julian F Guest ${ }^{1,2}$ \\ Fernando Moya $^{3}$ \\ Paula M Sisk ${ }^{4}$ \\ Mark L Hudak ${ }^{5}$ \\ Devon Kuehn ${ }^{6}$ \\ 'Catalyst Health Economics \\ Consultants, Northwood, Middlesex, \\ UK; ${ }^{2}$ Faculty of Life Sciences and \\ Medicine, King's College, London, \\ UK; ${ }^{3}$ Coastal Carolina Neonatology, \\ Wilmington, NC, USA; ${ }^{4}$ Novant Health \\ Forsyth Medical Center, Winston \\ Salem, NC, USA; ${ }^{5}$ Department of \\ Pediatrics, University of Florida \\ College of Medicine, Jacksonville, \\ FL, USA; ${ }^{6}$ Department of Pediatrics, \\ East Carolina University, Greenville, \\ NC, USA
}

Correspondence: Julian F Guest

Catalyst Health Economics Consultants,

34b High Street, Northwood, Middlesex

HA6 IBN, UK

Tel +441923450045

Email julian.guest@catalyst-health.com
Objective: To estimate the cost-effectiveness of using a liquid human milk fortifier (LHMF) compared to a powdered human milk fortifier (PHMF) in preterm infants in the US from the perspective of third-party payers and parents.

Methods: This was a decision modelling study using patient data obtained from a randomized controlled trial comparing a LHMF with a PHMF in preterm infants, supplemented with additional data obtained by performing a chart review among $79 \%$ of the trial patients. The model estimated the cost-effectiveness of LHMF versus PHMF in US\$ at 2014/2015 prices.

Results: More infants in the LHMF group were discharged home (92\% versus $89 \%)$ and more infants in the PHMF group were transferred to another unit (9\% versus 5\%). Gestational age was an independent predictor for being discharged home (odds ratio of 2.18; $p=0.006$ for each week of gestational age). Mean length of neonatal intensive care unit (NICU) stay was 1 day less in the LHMF than the PHMF group (62.3 versus 63.4 days), but mean length of NICU stay among infants who developed NEC or sepsis was 79.3 days and 61.2 days in the PHMF and LHMF groups, respectively. Total management cost up to discharge was $\$ 10,497$ per infant less in the LHMF group than the PHMF group (\$240,928 versus \$251,425).

Conclusion: Using LHMF instead of PHMF in preterm infants enabled resources to be freed-up for alternative use within the system. There is no health economic reason why LHMF should not be used in preference to PHMF in the NICU.

Keywords: cost-effectiveness, milk fortifiers, neonatal intensive care, preterm infants, US

\section{Introduction}

Fortification of human milk is indicated for supplying the required nutrients to support the rapid rate of growth and bone mineralization in preterm infants. ${ }^{1}$ HMFs are nutritional supplements designed to increase total energy, protein, and micronutrient delivery to preterm infants. The primary benefits of human milk fortification include improved growth, bone mineralization, and protein status. ${ }^{2-4}$ It is common practice in NICUs to add liquid or powdered fortifiers to an infant's feed to better meet the protein needs of smaller preterm infants. However, powdered HMFs fail to meet the recommended safety guidelines designed to decrease the risk of transmission of pathogens, such as Cronobacter sakazakii and other infectious complications, in the NICU. ${ }^{5-7}$ Consequently, during the last decade, there has been a gradual transition to sterile liquid nutritionals in the neonatal environment. Unlike powdered nutritionals, LHMFs may have the advantage of sterility and simpler liquid-liquid mixing with human milk.

A recent multicenter, third-party-blinded, randomized controlled study, in which the clinical investigators, all NICU personnel and sponsor personnel who were submit your manuscript f in 
monitoring the study were unaware of treatment assignment, compared a LHMF with a PHMF in preterm infants to evaluate the growth, tolerance, and safety. ${ }^{8}$ One hundred and fifty preterm infants with a body weight $\leq 1,250 \mathrm{~g}$ who were fed expressed and/or donor breast milk were randomized to receive a PHMF or LHMF for 28 days. The study found that the achieved weight and linear growth rate were significantly higher in the LHMF group ( $p=0.04$ and $p=0.03$, respectively). Among the infants who adhered closely to the protocol, the LHMF group achieved a significantly higher weight, length, head circumference and linear growth rate than infants in the PHMF group ( $p=0.004, p=0.003, p=0.04$, and $p=0.01$, respectively). However, there were no differences in measures of feeding tolerance or days to achieve full feeding volumes. Prealbumin, albumin, and blood urea nitrogen were all higher in the LHMF group $(p<0.05)$. There was no difference in the incidence of confirmed sepsis or NEC. Hence, use of LHMF in preterm infants instead of PHMF was found to improve growth and afford a safe alternative.

The comparative health economic impact of these two fortifiers is unknown, and therefore, dietetic choices are based largely on their safety, nutritional value, and purchase cost. Hence, the objective of the current study was to use data from the patients who participated in the aforementioned trial to estimate the cost-effectiveness of using LHMF compared to PHMF in preterm infants in the US, from the perspective of third-party payers and parents.

\section{Methods}

\section{Study design}

This was a retrospective modelling study using patient data obtained from the aforementioned clinical trial, ${ }^{8}$ together with additional data from a sample of the trial patients subsequently obtained by performing a chart review.

\section{Chart review}

All 14 centers that participated in the trial ${ }^{8}$ were invited to participate in the chart review. However, only 9 centers agreed to participate. The other 5 centers chose not to participate because either the principal investigator had left, or there was a lack of interest, or it was not feasible to retrieve the patients' records, or too few patients were enrolled in the original trial.

Hence, IRB approval was obtained to undertake the chart review at 9 of the 14 clinical trial centers from The New Hanover Regional Medical Centre Institutional Review Board (Reference \# 1410-5). Approval was given for a member of the clinical staff at each center to conduct the chart review and to then forward the collected data, once anonymized, to the study's authors in order for them to perform an economic analysis. The chart review recorded:

- Length of stay in the NICU;

- Body weight at discharge;

- Body length at discharge;

- Head circumference at discharge;

- Disposition on discharge.

\section{Statistical analyses}

The ITT population from the original trial was balanced and there were no significant differences in baseline variables between the two groups. ANCOVA found that the baseline variables in the two treatment groups in the chart review population were balanced and no adjustments were necessary.

Differences in health outcomes and resource use between the two groups in the chart review population were tested for statistical significance using a Mann-Whitney $U$-Test, independent samples $t$-test, and a Chi-Square test. Logistic regression was used to investigate relationships between baseline variables and the probability of being discharged home. Multiple linear regression was also used to assess the impact of patients' baseline variables on resource use and clinical outcomes. All statistical analyses were performed using SPSS Statistics (v22.0; IBM Corporation, Armonk, NY, USA).

\section{Economic model}

A decision model (Figure 1) was constructed using TreeAge Pro 2009 (TreeAge Software Inc., Williamstown, MA, USA) depicting the management of preterm infants who were managed with LHMF or PHMF. The model was populated with patient-level data from the aforementioned clinical trial, ${ }^{8}$ and additional data obtained from the chart review. The period of the model was up to discharge from the NICU or death if that occurred earlier. The primary measure of clinical effectiveness in the model was the probability of infants being discharged home.

Unit costs obtained from the MarketScan Commercial Claims Database, and uprated to 2014/2015 prices using the US inflation indexes, were assigned to the estimates of resource use in the model in order to calculate the cost of managing patients in each group at 2014/2015 prices.

The cost-effectiveness of LHMF versus PHMF was calculated as: the difference in the cost of patient management between the two groups divided by the difference in the probability of being discharged home between the two 


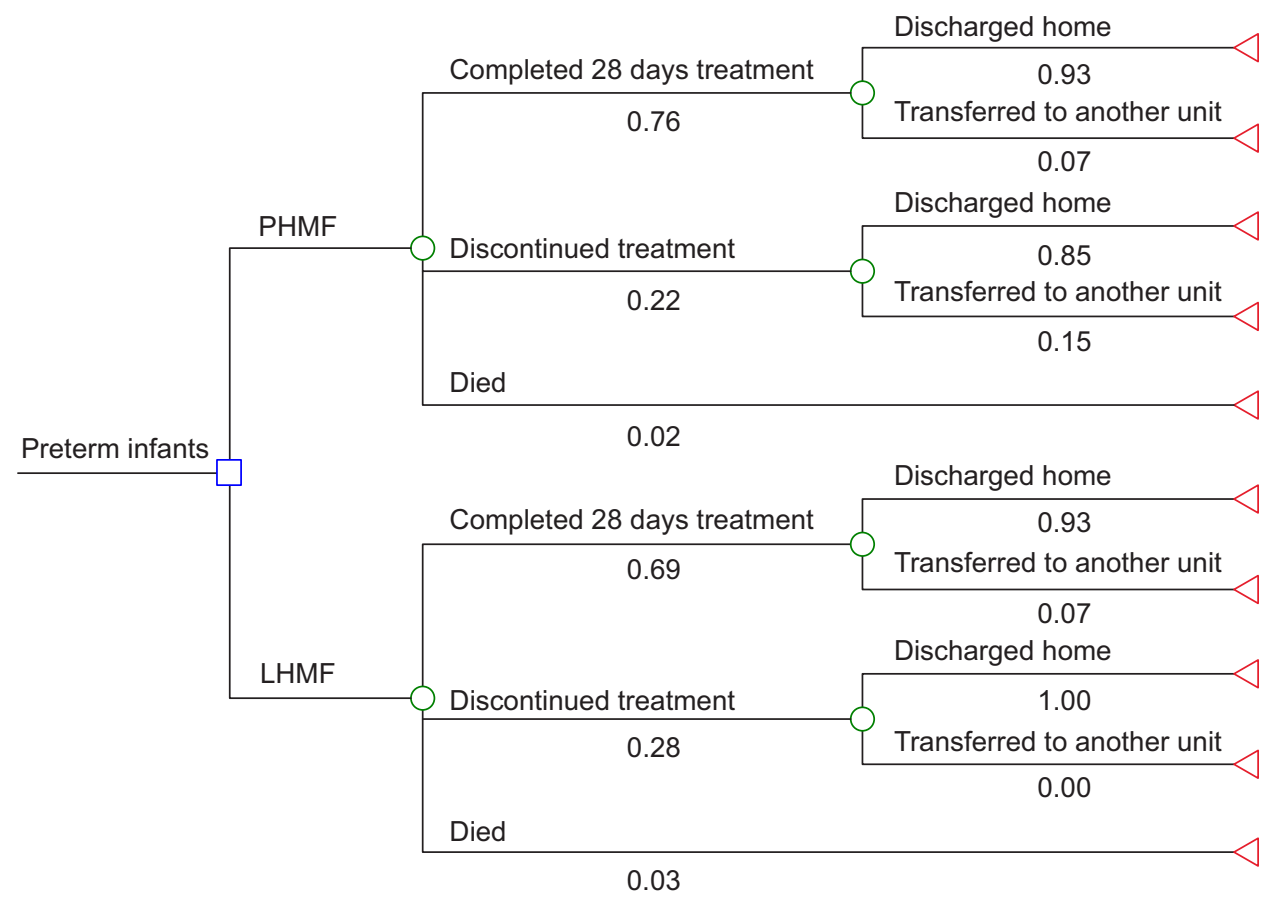

Figure I Decision model depicting the management of infants in the chart review population.

Note: Numbers denote the probability of an infant following a particular path.

Abbreviations: LHMF, liquid human milk fortifier; PHMF, powdered human milk fortifier.

groups, expressed as the incremental cost for each additional infant who was discharged home. If one fortifier improved the probability of being discharged home for less cost, it was considered a dominant (ie, cost-effective) treatment.

\section{Sensitivity analyses}

To assess uncertainty within the model, probabilistic sensitivity analysis was undertaken $(10,000$ iterations of the model $)$ to estimate the distribution of 1) costs and 2) probabilities of being discharged home. This was achieved by simultaneously varying the probabilities, clinical outcomes, resource use values and unit costs within the model. Outputs from these analyses were used to estimate the probability of being cost-effective at different thresholds of incremental cost per additional infant who was discharged home.
In addition, deterministic sensitivity analyses were performed to identify how the incremental cost-effectiveness of LHMF compared to PHMF would change by varying different parameters in the model.

\section{Results}

\section{Infants' characteristics}

From the chart review, additional data were obtained on $79 \%$ of the patients who were in the ITT cohort. The baseline characteristics of infants in the chart review cohort were not significantly different from the whole ITT cohort. Any differences between the ITT and chart review populations can be explained by different sample sizes, implying the chart review population was sufficiently representative of all the infants who participated in the trial (Table 1).

Table I Infants' baseline characteristics

\begin{tabular}{|c|c|c|c|c|}
\hline & \multicolumn{2}{|c|}{ ITT population } & \multicolumn{2}{|c|}{ Chart review population } \\
\hline & LHMF & PHMF & LHMF & PHMF \\
\hline Sample size & 74 & 72 & 57 & 59 \\
\hline Percentage female & $50 \%$ & $56 \%$ & $51 \%$ & $53 \%$ \\
\hline Mean $( \pm S D)$ gestational age per infant (weeks) & $27.9 \pm 1.4$ & $27.7 \pm 1.8$ & $27.6 \pm 1.5$ & $27.1 \pm 1.8$ \\
\hline Mean $( \pm S D)$ body weight per infant at day $0(\mathrm{~g})$ & $1014.7 \pm 171.6$ & $987.1 \pm 197.7$ & $1140.3 \pm 176.8$ & $1082.8 \pm 188.8$ \\
\hline Mean $( \pm S D)$ body length per infant at day $0(\mathrm{~cm})$ & $36.1 \pm 3.3$ & $35.6 \pm 2.9$ & $35.8 \pm 3.7$ & $35.4 \pm 3.1$ \\
\hline Mean $( \pm S D)$ head circumference per infant at day $0(\mathrm{~cm})$ & $25.0 \pm 1.7$ & $25.1 \pm 1.7$ & $25.1 \pm 1.7$ & $24.9 \pm 1.8$ \\
\hline Mean $( \pm S D)$ number of sachets/vials of fortifier per infant over 28 days of treatment & $293.4 \pm 222.0$ & $297.0 \pm 216.8$ & $298.8 \pm 238.9$ & $306.5 \pm 230.5$ \\
\hline
\end{tabular}

Abbreviations: ITT, intention-to-treat; LHMF, liquid human milk fortifier; PHMF, powdered human milk fortifier. 


\section{Probability of being discharged home}

The probability of infants being discharged home was not significantly different between the two groups, although marginally more infants in the LHMF group were discharged home ( 0.92 versus 0.89$)$ or died ( 0.03 versus 0.02$)$ and marginally more infants in the PHMF group were transferred to another unit (0.09 versus 0.05$)$.

Binary logistic regression showed, as expected, that gestational age was an independent predictor for being discharged home (odds ratio of 2.18 [95\% CI: $1.25 ; 3.70] ; p=0.006$ for each week of gestational age).

\section{Health outcomes and resource use}

At the time of discharge from the NICU, there were no significant differences in body weight, body length or head circumference between the two groups (Table 2). Additionally, there was no significant difference in the mean length of stay in the NICU between the two groups (Table 2).

There was no significant difference $(p>0.25)$ in the incidence of infants who developed NEC or sepsis between the two groups either in the trial ${ }^{8}$ or the chart review population (Table 2). However, in the PHMF chart review population one infant had a combination of sepsis and NEC, whereas in the LHMF group three infants had a combination of sepsis and NEC. Of these, one infant in the LHMF group had multiple episodes of sepsis. All the other affected infants

Table 2 Infants' health outcomes and health care costs in US\$ (at 2014/2015 prices)

\begin{tabular}{|c|c|c|}
\hline & \multicolumn{2}{|c|}{ Chart review population } \\
\hline & LHMF & PHMF \\
\hline \multicolumn{3}{|l|}{ Health outcomes } \\
\hline $\begin{array}{l}\text { Mean }( \pm S D) \text { body weight per infant at } \\
\text { discharge }(g)\end{array}$ & $2295.2 \pm 595.3$ & $2203.7 \pm 581.4$ \\
\hline $\begin{array}{l}\text { Mean }( \pm S D) \text { body length per infant at } \\
\text { discharge }(\mathrm{cm})\end{array}$ & $44.2 \pm 3.4$ & $43.8 \pm 4.1$ \\
\hline $\begin{array}{l}\text { Mean }( \pm S D) \text { head circumference per } \\
\text { infant at discharge }(\mathrm{cm})\end{array}$ & $31.6 \pm 2.6$ & $31.5 \pm 3.6$ \\
\hline Percentage with NEC or sepsis & $21 \%$ & $17 \%$ \\
\hline $\begin{array}{l}\text { Mean ( } \pm \text { SD) length of time in the } \\
\text { NICU (days) }\end{array}$ & $62.3 \pm 24.6$ & $63.4 \pm 25.2$ \\
\hline \multicolumn{3}{|l|}{ Management costs } \\
\hline $\begin{array}{l}\text { Mean }( \pm S D) \text { NICU cost per infant to } \\
\text { third-party payers }\end{array}$ & $\$ 236,394.90$ & $\$ 246,558.50$ \\
\hline $\begin{array}{l}\text { Mean }( \pm S D) \text { fortifier cost per infant to } \\
\text { third-party payers }\end{array}$ & $\$ 527.00$ & $\$ 327.00$ \\
\hline $\begin{array}{l}\text { Mean }( \pm S D) \text { NICU cost per infant to } \\
\text { parents }\end{array}$ & $\$ 4,006.10$ & $\$ 4,539.50$ \\
\hline $\begin{array}{l}\text { Mean }( \pm S D) \text { total gross cost per } \\
\text { infant }\end{array}$ & $\$ 240,928.00$ & $\$ 25 I, 425.00$ \\
\hline
\end{tabular}

Abbreviations: LHMF, liquid human milk fortifier; NEC, necrotising enterocolitis; NICU, neonatal intensive care unit; PHMF, powdered human milk fortifier. either had one episode of sepsis or NEC. The mean length of NICU stay of infants who developed these comorbidities was 79.3 days in the PHMF group and 61.2 days in the LHMF group. In contrast, the length of NICU stay of infants who did not develop NEC or sepsis was a mean of 62.7 days in both groups.

There were no differences in length of stay in the NICU between the two groups when stratified according to gestational age. Those infants with a gestational age $\leq 27$ weeks had a length of stay in the NICU of a mean of 74-76 days per infant, irrespective of fortifier. In comparison, those infants with a gestational age $>27$ weeks had a length of stay in the NICU of a mean of 51-53 days per infant.

Linear regression showed that gestational age, head circumference at birth, and body length at birth were independent predictors of length of stay in the NICU. The length of stay in the NICU would be reduced by:

- 4 days for each week of gestational age $(p<0.001)$;

- 2.5 days for each $\mathrm{cm}$ of head circumference at the start of treatment $(p=0.001)$;

- 1 day for each $\mathrm{cm}$ of body length at the start of treatment $(p=0.004)$.

Head circumference and body length are surrogates for the type of intrauterine growth and relate directly to gestational age. Hence, they relate to length of stay. Feeding strategies can also influence head circumference and body length after birth, both of which impact on body weight. Consequently, body weight is one of the major factors a neonatologist considers when deciding to discharge an infant from the NICU.

\section{Health care cost of infant management}

The total management cost up to discharge was $\$ 240,928 \pm 36,979$ per LHMF-treated infant and $\$ 251,425 \pm 38,488$ per PHMF-treated infant. Hence, the total cost of infant management up to the time of discharge was $\$ 10,497$ per infant less in the LHMF group than the PHMF group (Table 2).

The total cost to third-party payers was $\$ 236,922$ per LHMF-treated infant and \$246,886 per PHMF-treated infant. The corresponding cost to parents was $\$ 4,006$ and $\$ 4,540$ per infant in the LHMF and PHMF groups, respectively. Hence, the cost per infant to third-party payers and parents was $\$ 9,964$ and $\$ 533$, respectively less in the LHMF group than the PHMF group (Table 2).

The primary cost driver was length of stay in the NICU, accounting for $99 \%$ of the cost to third-party payers. Fortifiers accounted for $<1 \%$ of costs to third-party payers, and parents' 
costs account for $2 \%$ of the gross cost. Parents do not contribute to the cost of fortifiers.

Since the mean length of NICU stay of infants who developed NEC or sepsis was 18.1 days more in the PHMF group, the total cost of management of these infants was $\$ 304,428$ and $\$ 219,085$ per infant in the PHMF and LHMF groups, respectively. In contrast, the cost of managing infants who did not develop NEC or sepsis was a mean of $\$ 242,548$ per infant.

The cost of managing infants with a gestational age $\leq 27$ weeks was a mean of $\$ 300,000$ per infant irrespective of treatment group, which was reduced to a mean of $\$ 194,000$ per infant who had a gestational age $>27$ weeks.

\section{Cost-effectiveness analysis}

Proportionally more infants in the LHMF group were discharged home compared to those in the PHMF group. Additionally, feeding infants with LHMF reduced management costs when compared to feeding infants with PHMF. Hence, use of LHMF instead of PHMF was found to be the dominant strategy, because it improved outcome for less cost, from the perspective of both third-party payers and parents (Table 3).

\section{Sensitivity analyses}

Probabilistic sensitivity analyses estimated the distribution of expected costs and probabilities of being discharged home (Figure 2). Using these distributions, the probability of LHMF being cost-effective was found not to exceed 0.6 (Figure 3 ). In other words, no more than $60 \%$ of a cohort is expected to be cost-effectively treated with LHMF, and that up to $40 \%$ of a cohort could be cost-effectively treated with PHMF, from a gross perspective.

Deterministic sensitivity analyses (Table 4) showed that the results are extremely sensitive to the probability of

Table 3 Cost-effectiveness analysis

\begin{tabular}{|c|c|c|c|c|c|}
\hline & $\begin{array}{l}\text { Mean } \\
\text { cost per } \\
\text { infant }\end{array}$ & $\begin{array}{l}\text { Probability } \\
\text { of being } \\
\text { discharged home }\end{array}$ & Cost-difference & $\begin{array}{l}\text { Difference in } \\
\text { probability of } \\
\text { being discharged home }\end{array}$ & $\begin{array}{l}\text { Incremental cost for } \\
\text { each additional infant } \\
\text { being discharged home }\end{array}$ \\
\hline \multicolumn{6}{|c|}{ Gross perspective } \\
\hline LHMF & $\$ 240,928$ & 0.92 & & & Dominant \\
\hline PHMF & $\$ 251,425$ & 0.89 & $-\$ 10,497$ & 0.03 & Dominated \\
\hline \multicolumn{6}{|c|}{ Third-party payers' } \\
\hline \multicolumn{6}{|c|}{ perspective } \\
\hline LHMF & $\$ 236,922$ & 0.92 & & & Dominant \\
\hline PHMF & $\$ 246,886$ & 0.89 & $-\$ 9,964$ & 0.03 & Dominated \\
\hline \multicolumn{6}{|c|}{ Parents' perspective } \\
\hline LHMF & $\$ 4,006$ & 0.92 & & & Dominant \\
\hline PHMF & $\$ 4,540$ & 0.89 & $-\$ 534$ & 0.03 & Dominated \\
\hline
\end{tabular}

Note: Costs in US\$ (at 2014/2015 prices).

Abbreviations: LHMF, liquid human milk fortifier; PHMF, powdered human milk fortifier.

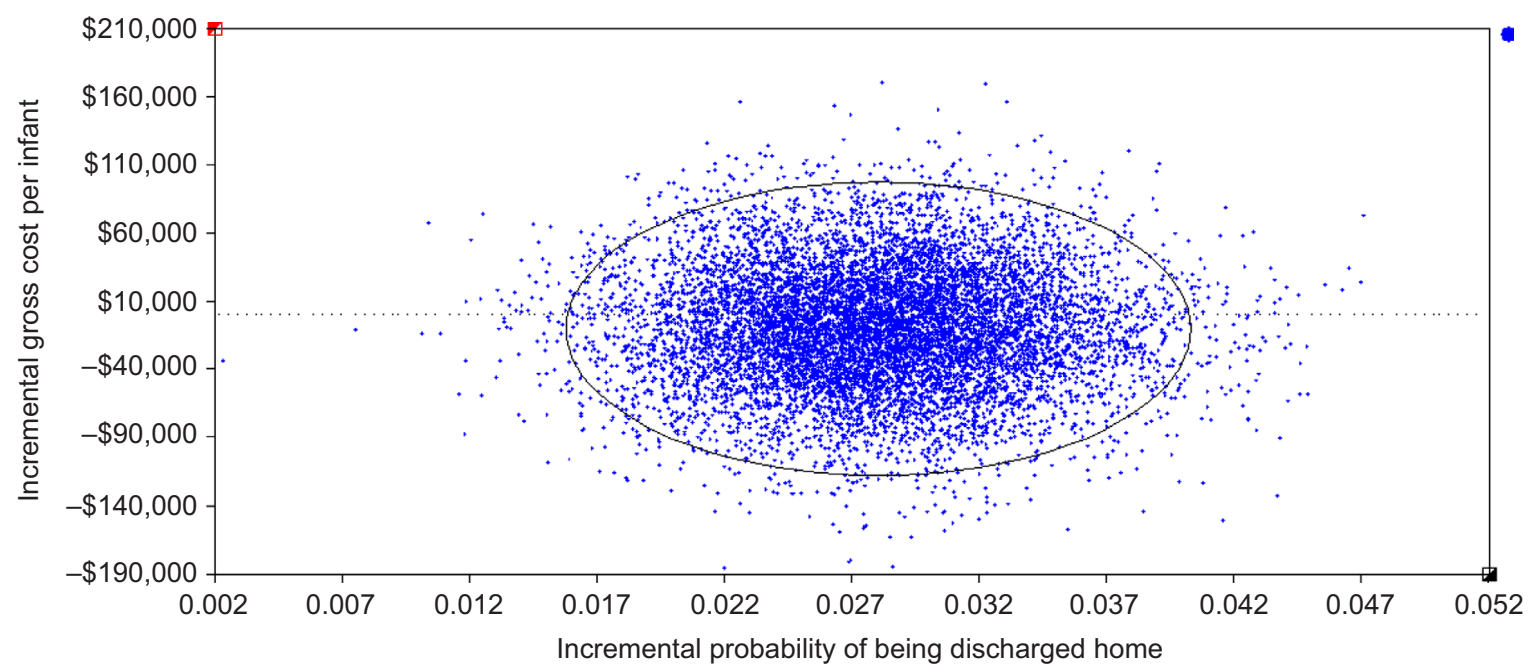

Figure 2 Scatterplot of the incremental cost-effectiveness of LHMF compared with PHMF (10,000 iterations of each model).

Notes: A beta distribution was used to represent uncertainty in probability values and a log-normal distribution was used to represent uncertainty in clinical outcomes and resource use estimates, by assuming a $5 \%$ standard deviation around the mean values. Unit costs were varied randomly according to a gamma distribution by assuming a $10 \%$ standard deviation around the mean values. Costs in US\$ (at 2014/2015 prices). 


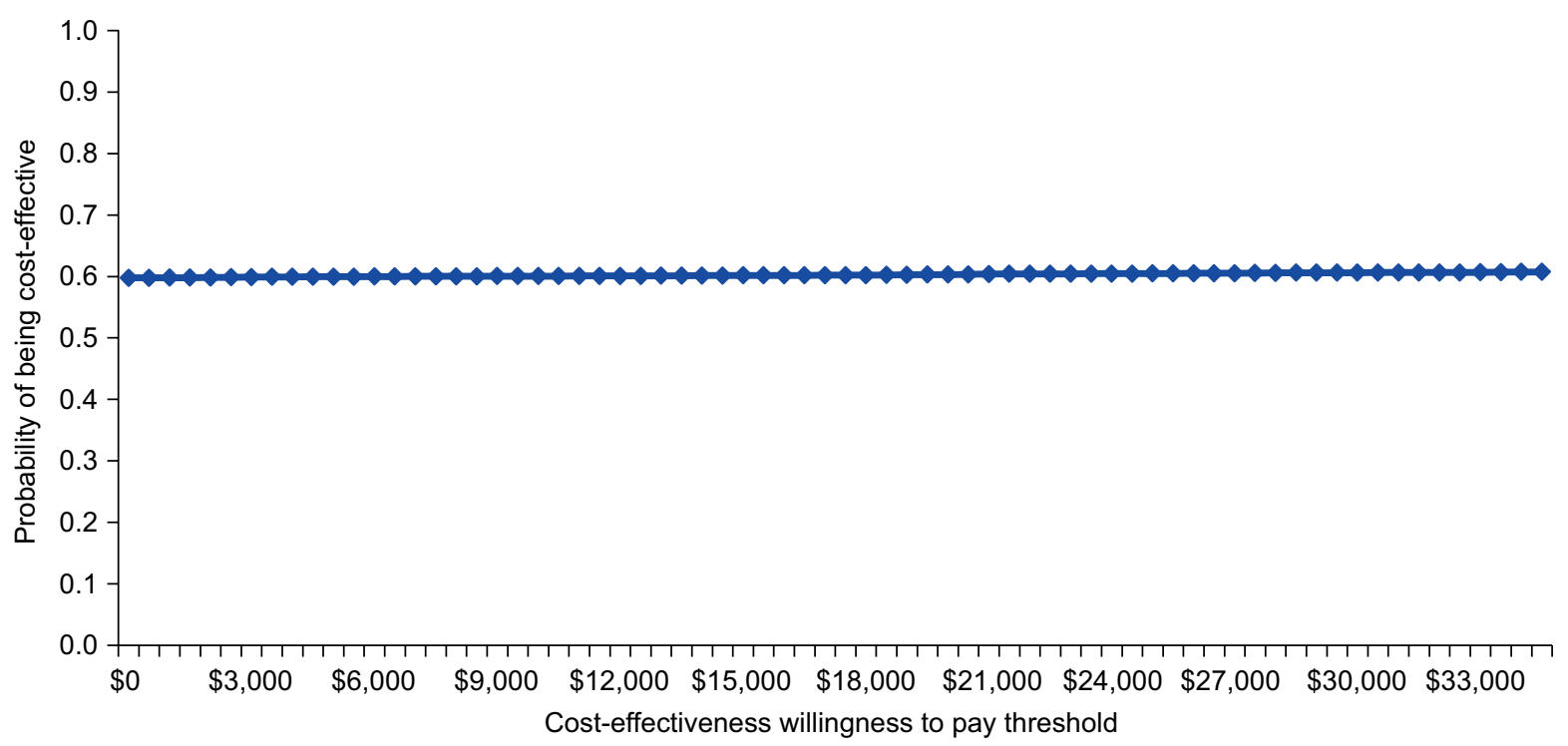

Figure 3 Cost-effectiveness acceptability curve.

Note: Costs in US\$ (at 2014/2015 prices).

Table 4 Deterministic sensitivity analyses

\begin{tabular}{|c|c|c|c|}
\hline Scenario & $\begin{array}{l}\text { Base case } \\
\text { value }\end{array}$ & Third-party payers' perspective & Parents' perspective \\
\hline $\begin{array}{l}\text { Probability of LHMF-treated } \\
\text { infants being discharged home } \\
\text { (range } 0 \text { to } 1.0 \text { ) }\end{array}$ & 0.92 & $\begin{array}{l}\text { PHMF becomes the cost-effective (dominant) } \\
\text { option when the probability falls below } 0.9\end{array}$ & $\begin{array}{l}\text { PHMF becomes the cost-effective } \\
\text { (dominant) option when the probability falls } \\
\text { below } 0.9\end{array}$ \\
\hline $\begin{array}{l}\text { Probability of PHMF-treated } \\
\text { infants being discharged home } \\
\text { (range } 0 \text { to } 1.0 \text { ) }\end{array}$ & 0.89 & $\begin{array}{l}\text { LHMF remains the cost-effective (dominant) } \\
\text { option below a probability of } 0.9\end{array}$ & $\begin{array}{l}\text { LHMF remains the cost-effective (dominant) } \\
\text { option below a probability of } 0.9\end{array}$ \\
\hline $\begin{array}{l}\text { Length of NICU stay among } \\
\text { LHMF-treated infants (range from } \\
50 \% \text { below to } 50 \% \text { above the base } \\
\text { case value) }\end{array}$ & 62.3 days & $\begin{array}{l}\text { As the length of NICU stay of LHMF-treated } \\
\text { infants increases above the base case value, } \\
\text { LHMF is no longer cost-effective since the } \\
\text { incremental cost for each additional infant } \\
\text { discharged home is }>\$ 486,000\end{array}$ & $\begin{array}{l}\text { As the length of NICU stay of LHMF-treated } \\
\text { infants increases by above the base case } \\
\text { value, LHMF is no longer cost-effective since } \\
\text { the incremental cost for each additional } \\
\text { infant discharged home is }>\$ 9,700\end{array}$ \\
\hline $\begin{array}{l}\text { Length of NICU stay among } \\
\text { PHMF-treated infants (range from } \\
50 \% \text { below to } 50 \% \text { above the base } \\
\text { case value) }\end{array}$ & 63.4 days & $\begin{array}{l}\text { As the length of NICU stay of PHMF-treated } \\
\text { infants decreases below the base case value, } \\
\text { LHMF is no longer cost-effective since the } \\
\text { incremental cost for each additional infant } \\
\text { discharged home is }>\$ 524,000\end{array}$ & $\begin{array}{l}\text { As the length of NICU stay of PHMF-treated } \\
\text { infants decreases below the base case value, } \\
\text { LHMF is no longer cost-effective since the } \\
\text { incremental cost for each additional infant } \\
\text { discharged home is }>\$ 13,500\end{array}$ \\
\hline $\begin{array}{l}\text { Number of LHMF vials (range from } \\
50 \% \text { below to } 50 \% \text { above the base } \\
\text { case value) }\end{array}$ & 301 vials & $\begin{array}{l}\text { LHMF remains the cost-effective (dominant) } \\
\text { option }\end{array}$ & $\mathrm{N} / \mathrm{A}$ \\
\hline $\begin{array}{l}\text { Number of PHMF sachets (range } \\
\text { from } 50 \% \text { below to } 50 \% \text { above the } \\
\text { base case value) }\end{array}$ & 305 sachets & $\begin{array}{l}\text { LHMF remains the cost-effective (dominant) } \\
\text { option }\end{array}$ & N/A \\
\hline $\begin{array}{l}\text { Cost per day in the NICU for } \\
\text { infants who are discharged home } \\
\text { (range } \$ 3,000 \text { to } \$ 4,000 \text { per day) }\end{array}$ & $\$ 3,668$ per day & $\begin{array}{l}\text { LHMF remains the cost-effective (dominant) } \\
\text { option }\end{array}$ & $\begin{array}{l}\text { LHMF remains the cost-effective (dominant) } \\
\text { option }\end{array}$ \\
\hline $\begin{array}{l}\text { Cost per day in the NICU for } \\
\text { infants who are transferred to } \\
\text { another unit (range } \$ 6,500 \text { to } \\
\$ 7,500 \text { per day) }\end{array}$ & $\$ 7,06$ I per day & $\begin{array}{l}\text { LHMF remains the cost-effective (dominant) } \\
\text { option }\end{array}$ & $\begin{array}{l}\text { LHMF remains the cost-effective (dominant) } \\
\text { option }\end{array}$ \\
\hline
\end{tabular}

Note: Costs in US\$ (at 2014/2015 prices).

Abbreviations: LHMF, liquid human milk fortifier; NICU, neonatal intensive care unit; PHMF, powdered human milk fortifier; N/A, Not applicable. 
being discharged home and the length of stay in the NICU. Changes in these values could result in PHMF becoming the cost-effective option. Conversely, the results are insensitive to changes in quantity of fortifier fed to the infants.

\section{Discussion}

This retrospective modelling study depicted the management of preterm infants with a body weight $\leq 1,250 \mathrm{~g}$ and gestational age $\leq 30$ and $3 / 7$ weeks who were managed with either a LHMF or a PHMF. The economic analysis was based on data obtained from a chart review of $79 \%$ of the ITT cohort from the aforementioned study. ${ }^{8}$ The baseline characteristics of the chart review population were found to be representative of all the infants in the ITT cohort.

There were no differences in achieved body weight, body length, or head circumference at discharge between the LHMF and PHMF groups. This is in contrast with the significant differences in those parameters which were shown at the end of the 28-day study period in the original trial. ${ }^{8}$ This may reflect the fact that the sample size of the chart review population was smaller and once the study period ended in the original trial, all infants reverted to a nutritional regimen that included a lower intake of protein and potential energy, at a time when many infants were still below 34-35 weeks of corrected age with higher nutritional demands. Notwithstanding this, infants in the LHMF group had nonsignificant lower birth lengths and birth weights. Additionally, the LHMF had $\sim 20 \%$ more protein than the PHMF. ${ }^{8}$ However, it is highly unlikely that these differences had any bearing on length of stay and the decision to discharge an infant from the NICU during the blinded study. Moreover, the fortification of the LHMF was initiated almost a full day later, which would have put the infants in that group at a relative disadvantage. Body weight at discharge was not significantly different between the two groups, but was almost $100 \mathrm{~g}$ higher in the LHMF group. This difference was much higher than that observed at birth and is clinically important, since body weight is a far more important determinant of the time of discharge than some other variables.

Whilst this study focused on the cost-effectiveness of alternative human milk fortifiers, there are additional health economic benefits associated with using human milk, particularly in relation to infants' morbidities. ${ }^{9}$ Infants born with a very low birth weight $(<1,500 \mathrm{~g})$ are at high risk of mortality and are reported to be some of the most expensive patients in a US hospital. ${ }^{10}$ Such infants are susceptible to prematurityrelated morbidities, such as late-onset sepsis and NEC, which have health economic consequences. ${ }^{9}$ Human milk has been shown to reduce both the incidence and severity of some of these morbidities and, therefore, has an indirect impact on reducing the cost of NICU hospitalization. ${ }^{9}$

A diagnosis of NEC in very low birth weight infants has been shown to impose a significant additional financial burden to individual patients as well as the neonatal community as a whole. ${ }^{11}$ The mean length of NICU stay of infants in our chart review cohort who had NEC or sepsis was 79.3 days in the PHMF group and 61.2 days in the LHMF group. Moreover, the difference in length of stay between infants without NEC or sepsis and those with NEC or sepsis in the LHMF group was similar. Although these findings were based on a small number of subjects, they were not truncated due to death and thus represent real values. A larger cohort of infants would need to be studied to confirm this preliminary finding. The mean cost of care for infants in our chart review cohort who had NEC or sepsis was $\$ 304,428$ in the PHMF group and $\$ 219,085$ in the LHMF group. In contrast, the cost of care for the infants who did not develop NEC or sepsis was a mean of $\$ 242,548$ per infant. Feeding extremely premature infants in the NICU with a $100 \%$ human milk-based diet that includes mother's milk fortified with donor human milkbased HMF compared with bovine milk-based supplements may prevent $\mathrm{NEC}^{12,13}$ and thereby reduce hospital stay ${ }^{14}$ and generate savings in medical care resource use. ${ }^{12,13}$

The infants in our study were located across four states (Florida, Illinois, North Carolina, Virginia), had a mean gestational age of 27 weeks per infant and a length of stay in the NICU of a mean of 62-63 days per infant. However, those with a gestational age $\leq 27$ weeks had a length of stay in the NICU of a mean of 74-76 days per infant irrespective of treatment group, compared to 51-53 days per infant with a gestational age $>27$ weeks. Furthermore, regression analysis showed that the length of stay in the NICU was reduced by 4 days for each week of gestational age. This is consistent with the findings of others. In a Californian study the mean length of stay of neonatal care ranged from 83.3 days for those infants with a gestational age of 25 completed weeks, to 2.6 days for those infants with a gestational age of 37 completed weeks. ${ }^{15}$ It is also concordant with an analysis of a US national database which found that the length of hospital stay in late preterm infants is associated with multiple demographic and clinical factors. ${ }^{16}$ Factors associated with a length of stay of $>3$ days included gestational age of $<35$ weeks and birth weight of $<2,500$ g. ${ }^{16}$ In the Californian study, the costs of hospital stay decreased with gestational age from a median of $\$ 279,286$ at 24 weeks to $\$ 761$ at 37 weeks (uprated to 2015 prices). ${ }^{15} \mathrm{In}$ our study, the cost of managing infants with a gestational age $\leq 27$ weeks was a mean $\$ 300,000$ per infant irrespective of treatment group, which was reduced to a mean of $\$ 194,000$ 
per infant with a gestational age $>27$ weeks. Another US study which compared feeding an entirely human milk-based diet with bovine-based fortifier and maternal milk or a mix of maternal milk, bovine-based fortifier and formula or formulafed infants found the total cost of hospitalization to range from $\$ 237,929$ to $\$ 345,024$ (uprated to 2015 prices) per infant. ${ }^{17}$ In comparison, the total gross cost per infant in our chart review cohort was $\$ 240,928$ in the LHMF group and $\$ 251,425$ in the PHMF group. Whilst this cost-difference is relatively small (only 4\%), the provision of a fortifier that adheres to new infection control guidelines and provides improved nutrition ${ }^{8}$ without increasing costs is advantageous.

Our study is subject to several limitations. The multicenter trial $^{8}$ was designed to assess the efficacy and safety of LHMF in preterm infants receiving human breast milk and not to assess its relative cost-effectiveness. Only infants for whom resource use data were obtained have been included in the economic analysis, although the baseline characteristics of the chart review cohort were similar to those of the patients in the ITT cohort. ${ }^{8}$ No information was available on the destination and associated costs of patients who were transferred and the study does not consider the costs and consequences of the infants once they have left the NICU. However, proportionally more infants in the PHMF group were transferred to other units and more infants in the LHMF group were discharged home. Consequently, if the management cost in the stepdown units had been included in the analysis, the cost-difference between the two groups would probably be greater than our estimated value of $\$ 10,497$ per infant. Since more infants in the PHMF group were transferred to another facility, even if all these transfers were to a lower acuity facility for convalescence, the cost of managing infants would still be less in the LHMF group than the PHMF group. Furthermore, this was a blinded study and the clinicians who made the discharge decisions did not know which fortifier each infant received. Hence, the decision to discharge home or to another facility is unlikely to be subject to bias. Notwithstanding this, there was a 1-day nonsignificant difference in the mean length of NICU stay between the 2 groups, which accounted for the majority of the cost-difference. The possibility that other factors may contribute to economic differences between the two treatments cannot be excluded.

The analysis excluded the indirect costs incurred by society as a result of employed parents taking time off work and nontreatment-related costs incurred by parents. Also excluded are changes in health-related quality of life and improvements in general well-being of the infants and their parents as well as parents' preferences. Consequently, this study may have underestimated the relative cost-effectiveness of LHMF. The study was performed from the perspective of third-party payers and parents in the US. Therefore, generalizing this study's results to other publicly-funded health care systems would be challenging.

\section{Conclusion}

Within the study's limitations, using LHMF instead of PHMF in preterm infants enables resources to be freed up for alternative use within the system and there is no health economic reason why LHMF should not be used in preference to PHMF in the NICU.

Moreover, preterm births in the US impose a substantial burden on society. ${ }^{18}$ Hence, any intervention that reduces the use of health care resources, such as LHMF, has the potential to reduce this burden and such savings could be used to enhance the use of breast milk as the primary source of nutrition for all babies.

\section{Abbreviations}

HMFs: Human milk fortifiers

NICU: Neonatal intensive care unit

LHMF: Liquid human milk fortifier

PHMF: Powdered human milk fortifier

IRB: Institutional Review Board

ITT: Intention-to-treat

ANCOVA: Analysis of covariance

NEC: Necrotising enterocolitis

CI: Confidence intervals

US: United States

\section{Acknowledgments}

The authors thank Dr Bhagya Puppala, Department of Pediatrics, Division of Neonatology, Advocate Children's Hospital, Park Ridge, IL, US and Advocate Medical Group, Park Ridge, IL, US and Dr Raul A Lazarte, Fairfax Neonatal Associates, Inova Children's Hospital, Falls Church, VA, US for undertaking the chart review of their infants who participated in the original clinical trial. All phases of this study were funded by Mead Johnson Nutrition.

\section{Disclosure}

Fernando Moya received honoraria for lectures from Mead Johnson Nutrition. The authors report no other conflicts of interest in this work.

\section{References}

1. Carlson S, Wojcik B, Barker A, Klein J. Guidelines for the use of human milk fortifier in the neonatal intensive care unit. Available from: http:// www.uichildrens.org/iowa-neonatology-handbook/feeding/humanmilk. Accessed January 17, 2016. 
2. Kuschel CA, Harding JE. Multicomponent fortified human milk for promoting growth in preterm infants. Cochrane Database Syst Rev. 2004;1:CD000343.

3. Arslanoglu S, Bertino E, Coscia A, Tonetto P, Giuliani F, Moro GE. Update of adjustable fortification regimen for preterm infants: a new protocol. J Biol Regul Homeost Agents. 2012;26(3 Suppl):65-67.

4. Arslanoglu S, Moro GE, Ziegler EE. Adjustable fortification of human milk fed to preterm infants: does it make a difference? J Perinatol. 2006;26(10):614-621.

5. Taylor C. Health professionals letter on Enterobacter sakazakii infections associated with the use of powdered (dry) infant formulas in neonatal intensive care units. Bethesda, MD: US Food and Drug Administration, Center for Food Safety and Applied Nutrition, Office of Nutritional Products, Labeling and Dietary Supplements; 2002. Available from: http://www.fda.gov/Food/RecallsOutbreaksEmergencies/SafetyAlertsAdvisories/ucm111299.htm.

6. Baker RD. Infant formula safety. Pediatrics. 2002;110(4):833-835.

7. Steele C, Kinzler S. Microbiology and infection control. In: Robbins ST, Meyers R, eds. Infant feedings: guidelines for preparation of human milk and formula in health care facilities. 2nd ed. Chicago, IL: Diana Faulhaber; 2011:108-121.

8. Moya F, Sisk PM, Walsh KR, Berseth CL. A new liquid human milk fortifier and linear growth in preterm infants. Pediatrics. 2012;130: e928-935.

9. Johnson TJ, Patel AL, Bigger HR, Engstrom JL, Meier PP. Economic benefits and costs of human milk feedings: a strategy to reduce the risk of prematurity-related morbidities in very-low-birth-weight infants. $A d v$ Nutr. 2014;5:207-212.
10. Johnson TJ, Patel AL, Jegier BJ, Engstrom JL, Meier PP. Cost of morbidities in very low birth weight infants. J Pediatr. 2013;162(2): 243-249.

11. Bisquera JA, Cooper TR, Berseth CL. Impact of necrotizing enterocolitis on length of stay and hospital charges in very low birth weight infants. Pediatrics. 2002;109(3):423-428.

12. Ganapathy V, Hay JW, Kim JH. Costs of necrotizing enterocolitis and cost-effectiveness of exclusively human milk-based products in feeding extremely premature infants. Breastfeed Med. 2012;7(1): 29-37.

13. Sullivan S, Schanler RJ, Kim JH, et al. An exclusively human milkbased diet is associated with a lower rate of necrotizing enterocolitis than a diet of human milk and bovine milk based products. $J$ Pediatr. 2010;156(4):562-567.

14. Arnold LD. The cost-effectiveness of using banked donor milk in the neonatal intensive care unit: prevention of necrotizing enterocolitis. J Hum Lact. 2002;18(2):172-177.

15. Phibbs CS, Schmitt SK. Estimates of the cost of length of stay changes that can be attributed to one-week increases in gestational age for premature infants. Early Hum Dev. 2006;82(2):85-95.

16. Aly H, Hoffman H, El-Dib M, Said L, Mohamed M. Factor affecting length of stay in late preterm infants: an US national database study. J Matern Fetal Neonatal Med. 2015;28(5):598-604.

17. Assad M, Elliott MJ, Abraham JH. Decreased cost and improved feeding tolerance in VLBW infants fed an exclusive human milk diet. J Perinatol. 2016;36(3):216-220.

18. Behrman RE, Butler AS. Preterm birth: causes, consequences, and prevention. Washington (DC): National Academies Press, 2007.
ClinicoEconomics and Outcomes Research

\section{Publish your work in this journal}

ClinicoEconomics and Outcomes Research is an international, peerreviewed open-access journal focusing on health technology assessment, pharmacoeconomics and outcomes research in the areas of diagnosis, medical devices, and clinical, surgical and pharmacological intervention. The economic impact of health policy and health systems
Submit your manuscript here: https://www.dovepress.com/clinicoeconomics-and-outcomes-research-ourat

organization also constitute important areas of coverage. The manuscript management system is completely online and includes a very quick and fair peer-review system, which is all easy to use. Visit http://www.dovepress.com/testimonials.php to read real quotes from published authors. 